\title{
Lewin e a pesquisa-ação: gênese, aplicação e finalidade
}

\author{
Armando Sérgio Emerenciano de Melo, I Osterne Nonato Maia Filho, II, III Hamilton Viana Chaves, IV, ${ }^{I}$ \\ ${ }^{I}$ Universidade de Fortaleza, Fortaleza, CE, Brasil /II Universidade Estadual do Ceará, Fortaleza, CE, Brasil \\ III Universidade Federal do Ceará, Fortaleza, CE, Brasil \\ ${ }^{\text {IV }}$ Instituto Federal de Educação, Ciência e Tecnologia do Ceará, Fortaleza, CE, Brasil
}

\begin{abstract}
Resumo
O objetivo deste texto é refletir sobre a gênese, os fundamentos teóricos e a importância da pesquisa-ação como estratégia de intervenção psicológica. Pretende-se, a partir deste resgate, suprir uma demanda do pesquisador em psicologia: demarcar os fundamentos do surgimento da pesquisa-ação e viabilizar as bases cientificas de uma intervenção psicológica amparada neste método de trabalho. A pesquisa-ação pode ser pensada epistemologicamente como uma modalidade de pesquisa "qualitativa". Esta diferencia-se dos métodos de pesquisa tradicionais e positivistas, uma vez que esses estão mais ligados a uma noção reducionista de fenômeno humano, na lógica da categoria psicológica "experimental" e quantitativamente controlável.
\end{abstract}

Palavras-chave: pesquisa-ação; Kurt Lewin; fundamentos teóricos; grupo.

\section{Lewin and action research: genesis, application and purpose}

\begin{abstract}
The aim of this paper is to reflect on the genesis, the theoretical foundation and the importance of action research as a strategy for psychological intervention. It is intended, from this resumption, to fulfill the demand of a researcher in psychology: define the fundamental of the emerging of action research and facilitate the scientific basis of psychological intervention supported by this working method. Action research can be epistemologically considered as a form of "qualitative" research, differentiating itself from traditional and positivist research methods, which are more connected to a reductionist approach of human and psychological "experimental" phenomenon and quantitatively controllable.
\end{abstract}

Keywords: action research, Kurt Lewin; theoretical foundations; group.

\section{A pesquisa tradicional na psicologia e a pesquisa-ação}

A escolha do método de pesquisa-ação deve, inicialmente, levar em consideração sua história e sua fundamentação teórica e epistemológica. A pesquisa-ação como uma abordagem qualitativa de pesquisa tem sido objeto da reflexão de teóricos e epistemólogos tais como Alves (1991), Barbier (1985, 2007), Haguette (1997), Bogdan e Biklen (1994), Triviños (1992) e Tripp (2005).

Os dados obtidos numa pesquisa são denominados de qualitativos quando apresentam um caráter descritivo e rico de significados. A expressão pesquisa qualitativa é utilizada "como um termo genérico que agrupa diversas estratégias de investigação que partilham determinadas características" (BOGDAN; BIKLEN, 1994, p. 16). A operacionalização desses dados não se dá através do controle de variáveis, mas da investigação de fenômenos tais como se encontram em seu contexto e na riqueza de seu ambiente "natural". Mesmo que os investigadores, na pesquisa qualitativa, possam vir a selecionar questões específicas na medida em que recolhem os dados, a abordagem da investigação não é feita com o objetivo de responder a questões prévias ou de testar hipóteses. Para Bogdan e Biklen (1994, p. 16), os pesquisadores

[...] privilegiam, essencialmente, a compreensão dos comportamentos a partir da perspectiva dos sujeitos da investigação. As causas exteriores são consideradas de importância secundária. Recolhem normalmente os dados em função de um contato aprofundado com os indivíduos, nos seus contextos ecológicos naturais.

^Endereço para correspondência: Universidade de Fortaleza, Curso de Psicologia. Av. Washington Soares, 1321 - Edson Queiroz. CEP: 60811905 - Fortaleza CE - Brasil.E-mail: armandosemelo@gmail.com, osterne filho@uol.com.br, hamilton@unifor.br
Os dados principais são apreendidos em sua contextualidade em função da relação entre pesquisador e sujeito pesquisado, sendo consideradas de menor relevância as causas exteriores a esta relação. Para Alves (1991), a abordagem qualitativa parte do pressuposto de que o conjunto de expressões dos sujeitos, vinculado a seus valores e crenças, é dotado de sentidos. Seus efeitos não se dão a conhecer por meio do imediato, sendo necessária a interpretação do que se apresenta.

A constatação é de que certos conhecimentos só se revelam a partir da interação humana. Decorre daí o consenso entre os teóricos da pesquisa qualitativa de considerar o pesquisador como o principal sujeito no processo de observação, de diagnóstico e de intervenção (REY, 2002). Os fenômenos sociais só se revelam aos pesquisadores quando eles estão dispostos a se engajarem pessoalmente, observando, diagnosticando e intervindo nos processos de pesquisa (LEWIN, 1965).

Em outras palavras, os fenômenos sociais não podem ser observados do exterior nem de modo estático, porque assim eles não se tornam perceptíveis ao pesquisador que os apreende participando de sua construção. Segundo Bogdan e Biklen (1994), a pesquisa qualitativa tem cinco características ou tendências principais: 1 . A fonte direta dos dados é o ambiente "natural", em condições espontâneas; 2. A investigação qualitativa é tipicamente descritiva; 3 . O foco de interesse do pesquisador é o processo; 4. Há uma tendência para analisar os dados de forma indutiva; 5. O significado é vital.

Nessas cinco tendências apresentadas encontramos as principais características da pesquisa qualitativa. Como ponto de encontro das cinco tendências merece destaque 
a proximidade entre sujeito e objeto. A inserção e a vivência direta do pesquisador no contexto da pesquisa são necessárias para que o conhecimento seja construído. Isto remete também para a participação dos sujeitos pesquisados no processo de geração de conhecimento.

Haguette (1997) também situa a pesquisa-ação como uma alternativa aos métodos de pesquisa tradicional ${ }^{1} \mathrm{e}$ a inclui entre os métodos de investigação qualitativa. Para ela as metodologias qualitativas não devem ser entendidas como alternativas aos modelos quantitativos, apresentados frequentemente em oposição. Isto reflete uma visão maniqueísta e pouco dialética que encontra vantagens sumárias em um modelo e defeitos congênitos do outro. Admitem Bogdan e Biklen (1994), que a escolha da pesquisa qualitativa não supõe que foi preterida a pesquisa quantitativa, pois não há essa dicotomia no campo da investigação. De fato, para Triviños (1992, p. 118), "toda pesquisa pode ser, ao mesmo tempo, quantitativa e qualitativa", pois o quantitativo nada mais é do que uma expressão da qualidade manifesta em linguagem matemática, logo se trata de formas diferentes de expressar e descrever o objeto ressaltando mais seu aspecto dinâmico (quantidade) ou se seu aspecto descritivo (qualidade).

Os pesquisadores em antropologia e sociologia utilizam largamente a abordagem qualitativa há, pelo menos, um século, mas a expressão "investigação qualitativa" em certa oposição à pesquisa quantitativa apenas veio a ser empregada no final dos anos sessenta do século passado. Schwandt (2006) destaca que o arcabouço teórico deste tipo de pesquisa sedimenta-se em pressupostos interpretativos e hermenêuticos. Assim sendo, faz-se necessário conectar conceitos oriundos destes pressupostos com a realidade investigada e a partir dessa relação produzir novos conceitos.

\section{A gênese da pesquisa-ação}

Barbier (2007) afirma que a discriminação ao povo judeu, marcante no período da segunda grande guerra, influenciou as escolhas metodológicas de Kurt Lewin. Com efeito, segundo Mailhiot (1985), Lewin, em 1933, por ser judeu, foi obrigado pelos nazistas a deixar a Alemanha com sua família, pagando um resgate para não ser encerrado em um campo de concentração. É como se a indignação de Lewin com a opressão nazista se apresentasse na forma de uma indagação: como os judeus aceitaram passivamente a opressão nazista? Como poderia responder a essa indagação? Dito de outra forma, quem poderia dar uma resposta consistente a essa indagação?

Ao propor a pesquisa-ação, Lewin ousou não apenas estudar o problema in loco, mas participar do problema. Conviver com a dor dos sujeitos para compreender clinicamente o seu problema. Observar, descrever, analisar e devolver a escuta na busca do conhecimento.

\footnotetext{
O termo "pesquisa tradicional" é utilizado aqui para designar o método de investigação proposto por August Comte no século XIX. O modelo de pesquisa proposto por Comte baseava-se na criação de uma teoria geral da ciência de modo que se concebesse o mundo social no mesmo modelo das ciências naturais Apresenta como pressuposto a separação entre sujeito e objeto de pesquisa, a neutralidade e objetividade. Decorrem principalmente da "pesquisa tradicional" os métodos da investigação quantitativa.
}

Propôs que os objetos da pesquisa se transformassem em sujeitos e, assim, usufruíssem diretamente da produção do saber. Resolvendo seus próprios problemas para aprender a pesquisar, para aprender a se apropriar de sua realidade. A comunidade se torna, assim, o próprio pesquisador em ação mediado pelo proponente inicial da pesquisa.

Para Barbier (1985), assim como a sociologia americana investigou os problemas sociais nas zonas urbanas após a primeira guerra mundial, a pesquisa-ação se desenvolveu a partir do problema judeu e das questões de ordem prática, decorrentes da segunda guerra mundial. Para esse autor, a gênese social precede à gênese teórica.

De fato, os estudos utilizando a pesquisa-ação se intensificaram durante e depois desse período. Barbier (1985, p. 39) cita algumas das investigações realizadas:

[...] no setor da indústria vão tratar da 'decisão de grupo', da 'auto-organização' (Bavelas), da 'formação dos quadros dirigentes' (Lewin e French), da 'modificação dos estereótipos' (French), de 'como vencer a resistência à mudança' (Coch e French).

Ao chegar aos Estados Unidos, Lewin encontrou problemas sociais semelhantes àqueles vivenciados por ele na Alemanha, mas desta vez eram negros, mulheres e adolescentes de rua (gangues), em vez de judeus. Embora fossem grupos expressivos, estes eram excluídos das prioridades da sociedade norte-americana.

Em resumo, a pesquisa-ação é ao mesmo tempo uma metodologia de resolução de problemas psicossociais e uma investigação científica e teórica sobre o mesmo problema. Seu fundamento teórico é que se somos parte do problema, o grupo como um todo dinâmico do qual faço parte pode investigá-lo e propor soluções melhores do que um pesquisador isolado e externo ao grupo. Noutros termos, os sujeitos envolvidos na investigação são uma parte significativa do problema pesquisado e a sua resolução serão atravessadas pela mudança de comportamento deles na comunidade.

\section{Abrangência e aplicação da pesquisa-ação lewiniana}

Após situar a pesquisa-ação como uma abordagem qualitativa, apresentaremos agora uma revisão dos seus principais conceitos. Para tanto, serão discutidos os aportes produzidos por Kurt Lewin, assim como as contribuições de alguns de seus seguidores e comentadores tais como Mailhiot (1985), Tripp (2005), Haguette (1997), Maciel (1999), Thiollent (1998, 2000) e Barbier $(1985,2007)$.

Tripp (2005) afirma que a pesquisa-ação é amplamente utilizada por pesquisadores das ciências humanas e sociais. Ele destaca que esta modalidade de pesquisa possui um caráter cíclico, o que quer dizer que há uma atuação conjunta entre pesquisador e sujeitos desde a admissão da questão inicial até os efeitos resultantes do estudo.

No campo da saúde podemos citar, por exemplo, as pesquisas de Sommer (1999) e Williamson e Prosser (2002). Estes últimos autores concordam que a pesquisaação tem crescido em popularidade. Os resultados de pesquisa com esse aporte metodológico permitem 
mudanças de práticas e geração de novos conhecimentos, além de maior empoderamento e autonomia de seus participantes. Os autores ressaltam, entretanto, que dadas às características de imersão de pesquisadores no locus de estudo algumas ressalvas devem ser feitas. A primeira delas é quanto às consequências políticas do estudo, isso porque envolve uma série de padrões comportamentais que são postos em questão e que, de alguma forma, estão sujeitos à mudança como resultado do estudo.

Em segundo lugar, evidenciam os aspectos éticos, algo também destacado por Tripp (2005). É preciso deixar claro que a pesquisa-ação não oferece as mesmas garantias de confidencialidade e anonimato das informações se comparada com outros métodos de pesquisa. O que requer do pesquisador discutir e negociar este aspecto antes de iniciar seus trabalhos. Por último, a própria concepção de que os sujeitos envolvidos na pesquisa tomam parte nos relatos de estudo deixa-os em uma delicada situação quanto ao sigilo.

Lewin (1978) ao fundamentar esse método, conceitualmente destaca que a pesquisa-ação lida notadamente com dois tipos de problemas, considerados indissociáveis: o estudo amplo da sociedade e a análise da situação específica. O caráter peculiar da situação em estudo é determinado por uma análise científica dos fatos, denominada diagnóstico. O conhecimento aí produzido orienta à solução do problema através de uma ação planificada e conduzida pelo grupo.

Esse estudioso se refere à planificação nos seguintes termos: "o planejamento parte de algo assim como uma ideia geral. Por qualquer razão, parece conveniente atingir um determinado objetivo. Frequentemente, não fica muito clara a maneira de definir esse objetivo, e de como atingilo" (LEWIN, 1978, p. 219). Cabe a indagação: se não é claro onde queremos chegar? Como chegaremos lá?

Pode-se entender que quando Lewin (1978) propõe que o planejamento parta de uma "ideia geral", que, de início, nem sempre é muito clara, ele admite uma indefinição como guia inicial, estando esta na direção de um processo de esclarecimento. Ao afirmar que o planejamento "parte de algo" que "não fica claro" de início, ele propõe partir da indefinição para a definição e, portanto, apresenta um método de construção. Assim o esclarecimento da demanda é uma exigência metodológica da pesquisa-ação. A clarificação de como atingir os objetivos é uma construção realizada, a partir do diagnóstico e através de um planejamento pelos envolvidos na pesquisa, coletivamente.

O que não é claro, mas também serve de guia para o pesquisador, são as idealizações, como utopias. Este conceito foi criado pelo inglês Thomas Morus e quer dizer lugar (topos) que não existe (prefixo grego $u$, negação) em sua famosa obra homônima do século XVI. Löwy (1999, p. 13) define utopias como "aquelas ideias, representações e teorias que aspiram outra realidade, uma realidade ainda inexistente". A realidade inexistente será

Fractal, Rev. Psicol., v. 28 - n. 1, p. 153-159, 2016 construída a partir da transformação da situação atual. Para tanto Lewin (1978) propunha o planejamento como construção necessária para tornar real, o utópico.

Um pesquisador do social não pode navegar por utopias impunemente; estas são vistas como sonhos realizáveis, exequíveis. O planejamento deve partir de um plano global, de como atingir o objetivo, e o primeiro passo é avaliar a ideia com atenção especial considerando os meios disponíveis. Confrontar o ideal com o real dos recursos, geralmente escassos.

Nesse momento para a pesquisa-ação é importante a análise dos recursos com a participação de todos nela envolvidos. Assim, a produção do diagnóstico e do planejamento é uma oportunidade de participação coletiva. Ao final do processo, é realizada a análise dos resultados produzidos pela ação, que tem quatro momentos: verificar os resultados produzidos pela ação, avaliando se o que foi atingido está de acordo com as expectativas do grupo; proporcionar aos planejadores uma oportunidade de aprender, ou seja, de obter uma nova compreensão geral do problema; servir de base para o planejamento adequado do próximo passo e servir de referência para a modificação do plano originalmente estabelecido.

Ao obter uma nova compreensão, tanto o pesquisador quanto os sujeitos da pesquisa estão ampliando os seus conhecimentos. Podemos afirmar que a pesquisa-ação é orientada à resolução de problemas e motivada pelo desejo de mudança. O pesquisador deve considerar o potencial dos participantes da investigação para desenvolver algumas habilidades específicas para a efetivação da pesquisa, sendo necessária a vontade de aprender e o compromisso com as mudanças dos sujeitos investigados. Algumas das consequências esperadas na pesquisa-ação com a participação social, além da solução dos problemas, são as aquisições de novos conhecimentos e estratégias de intervenção na realidade. Quais os caminhos tomados por Lewin para efetivar a pesquisa-ação? A efetivação de suas ideias se deu pela transformação das comunidades em laboratórios sociais e pelo conhecimento desenvolvido sobre a dinâmica dos grupos

Lewin (1978, p. 215) utilizou, para propor a pesquisaação, o formato do seminário ${ }^{2}$ com trabalhadores sociais americanos. Ele partiu do contato que teve durante um ano e meio com um grande número de organizações e instituições. "Incluíam-se representantes de comunidades, sistemas escolares, escolas isoladas, organizações minoritárias de diferentes origens e objetivos". Ele propôs uma estratégia para a realização de seminários que denominou "laboratórios sociais" (workshops).

Definiu esse termo como um conjunto metodológico visando a mudanças interpessoais, grupais e intergrupais a partir da análise da participação no laboratório e do relato das ocorrências na comunidade. O objetivo do laboratório social era possibilitar a resolução de problemas sociais, aperfeiçoando simultaneamente a metodologia de intervenção. Decorria deste objetivo

${ }^{2} \mathrm{O}$ formato de seminário daquela época consistia em reunir e ouvir as diferentes entidades interessadas na resolução de um determinado problema social. Esse desenho de reunião, antes de Lewin, era destituído de sistematização e ocorria informalmente. 
enfrentar a resistência que o "novo" promovia. Para o pesquisador, eram dois os problemas: o primeiro era vencer a resistência que os novos modos de trabalho promoviam; e o segundo era manter a mudança, evitando os processos de sabotagem que frequentemente ocorriam após as inovações.

Como parte do método do laboratório social, que se realizava através de oficinas, Lewin (1978) propôs que, antes de iniciá-lo, os trabalhadores sociais de cada comunidade realizassem um diagnóstico. No seminário, de posse dos diagnósticos, os passos seguintes eram efetivados.

Em primeiro lugar havia a formação de grupos de trabalho no estilo seminário, mas que conservavam esta relação após o seu encerramento. Com esta estratégia, ele propunha que as pessoas passassem a trabalhar em grupo, enfrentando, juntas, os problemas comuns. Assim, elas desenvolviam métodos e criavam vínculos. Desta feita a equipe continuaria a interagir quando voltasse à comunidade local. Essa orientação seguia a lógica da investigação científica.

Outro cuidado era quanto ao registro dos acontecimentos dos seminários. A anotação dos dados não era uma prática própria deste tipo de atividade, mas sim da ciência. Ainda hoje diversos grupos e organizações que trabalham com o social não utilizam registros de trabalho com o objetivo de aperfeiçoar a sua prática, permanecendo no empirismo informal e na cultura oral.

Para aperfeiçoamento do processo havia uma metaavaliação. Alguns meses após a realização do seminário, um diagnóstico semelhante ao primeiro deveria ser aplicado. Este procedimento possibilitava a comparação entre os dois diagnósticos, sendo que o segundo permitia renovar o ciclo da pesquisa-ação.

A inovação de Lewin (1978) foi propor que o seminário se transformasse em um momento de pesquisa, com status de ciência. Os registros, ao final de cada dia de seminário, eram utilizados para realizar uma sessão de avaliação, na qual era feita a comparação dos resultados obtidos com os objetivos traçados. Desta forma, a avaliação de um dia era investida na realização do próximo seminário, sendo que fazê-lo, ainda em seu percurso, possibilitava que o seu resultado fosse aplicado imediatamente e se pudessem corrigir possíveis desvios. Este aspecto era considerado muito importante por ele, que assim o descreveu:

[...] fiquei profundamente impressionado com o extraordinário resultado pedagógico que essas reuniões de avaliação, ideadas com o propósito de registro científico, tiveram no processo de treinamento. A atmosfera de objetividade, a disposição do corpo docente de discutir abertamente seus erros, longe de prejudicar-lhes a posição, parecia conduzir a um aprofundamento da compreensão e àquela disposição de serena objetividade que em lugar algum é mais difícil de atingir que no campo das relações intergrupais, o qual está carregado de emotividade e rigidez de atitude, mesmo entre os chamados liberais e entre aqueles cuja tarefa é promover relações intergrupais
(LEWIN, 1978, p. 225).

Barbier (1985, p. 40) apresenta outra descrição desse momento, destaca que Lewin "descobre o Training-Group, graças à curiosidade dos alunos de um laboratório para a transformação pessoal, que queriam ouvir e comentar o que a equipe de observação e pesquisa achava dos seus comportamentos". Foi devido ao interesse dos seus alunos, contratados pelo Instituto de Tecnologia de Massachusetts (MIT), e que eram participantes de um programa que visava minimizar os conflitos raciais nos Estados Unidos, que foi descoberto o efeito educativo do feedback.

Desta forma, podemos observar que, enquanto a avaliação significa o exame dos efeitos e dos resultados alcançados à luz de definições prévias em um determinado evento, o feedback vai mais além, pois implica no aproveitamento efetivo dos efeitos avaliados na reformulação ou na repetição do processo considerado. Quando se embute a função de feedback em qualquer processo de trabalho (pesquisa, educação etc.), considerase que, da avaliação, é provido um retorno sistemático, alterando ou ajustando o andamento do processo por efeito dessa alimentação para o objetivo traçado.

A descoberta do feedback é apenas um dos achados que possibilitaram a definição de um novo campo de estudo. Lewin cunhou o termo "dinâmica de grupos" e lhe definiu os primeiros contornos com o objetivo de viabilizar a realização da pesquisa-ação. O termo "dinâmica" vem do sentido que a física lhe empresta, qual seja, contrário ao conceito de estática, que significa sem movimento. Assim, dinâmica encerra a ideia de movimento, ou seja, a concepção de que, nos grupos, ocorrem fenômenos que lhe dão movimento, ou melhor, vida. Nos grupos ocorrem fenômenos subjetivos e psicológicos que provocam movimento e apenas o estudo científico destes poderá desvelar esses fenômenos.

O laboratório, ou oficina, era um evento coletivo que reivindicava a participação das pessoas. A necessidade de resolverem problemas sociais em comum proporcionou a Lewin também um dos meios para tal fim, o trabalho em grupo. Mas para trabalhar em grupo foi necessária não apenas a organização, mas entender como as pessoas agem em grupo. Para viabilizar a pesquisa-ação era necessário compreender os fenômenos de grupo. Por esse motivo Barbier (1985) afirma que Lewin criou a dinâmica dos grupos como decorrência da pesquisa-ação, pois ela apenas pode ocorrer em grupo exigindo, assim, a compreensão de como eles funcionam.

O fato da pesquisa-ação apenas ocorrer em interação grupal exigiu a compreensão desse trabalho coletivo. Para Haguette (1997, p. 115), o imbricamento entre a pesquisa-ação e a dinâmica dos grupos é tal que o pesquisador "deve dominar as técnicas de dinâmica dos grupos e as teorias subjetivas que a informam". Afinal, a pesquisa-ação é literalmente a ação dinâmica dos grupos como pesquisador.

Decorre desta constatação que, para execução da pesquisa-ação, o investigador precisa ser qualificado em dinâmica dos grupos no papel de coordenador de 
grupo. Em resumo, ao executar a pesquisa-ação, o investigador apoia-se na estratégia da oficina social na qual os conhecimentos em dinâmica dos grupos são imprescindíveis, sendo necessário que o pesquisador tenha formação específica. É claro que o processo produzirá um deslocamento do sujeito da ação: do pesquisador original para os grupos (comunidade) como pesquisadores.

\section{Finalidade da pesquisa-ação lewiniana}

Para Lewin (1978, p. 216), pesquisa-ação é “um tipo de pesquisa de ação, uma pesquisa comparativa acerca das condições e resultados de diversas formas de ação social e pesquisa que leva à ação social". Ele propôs como objetivo da pesquisa-ação, além da investigação teórica, a resolução do problema social. A necessidade de resolver problemas sociais tem implicações para o sistema teórico que ampara a leitura e interpretação desses problemas. Nesta perspectiva, é a resolução do problema social que influencia a investigação teórica. Thiollent (2000, p. 50) confirma esta implicação ao afirmar que o tema na pesquisa-ação "é a designação do problema prático e da área de conhecimento a serem abordados" e ao postular que não havia nada mais prático que uma boa teoria, Lewin propunha uma vinculação estreita entre o problema teórico e o prático.

Barbier (2007) apresenta uma definição de pesquisaação que contempla outros aspectos apresentados por Lewin. Ele afirma que a pesquisa-ação é um estudo do psicológico cujo objetivo é a transformação psicossocial a partir do trabalho de campo.

Entende-se como psicossocial o fenômeno que é simultaneamente social e psicológico, em que o efeito da interação social é assumido pelo sujeito psicológico como sendo seu e sentido pelo grupo social, como a unidade dessa diversidade. O sujeito psicológico sente essa experiência como algo que parte da vivência primeira, não mediada, mas não se limitaria por esta condição. Ele explora os diversos sentidos no intuito de apreender, mesmo que parcialmente, a realidade (FIGUEIREDO; SANTI, 2007).

Desvelar os sentidos ocultos da vivência é um processo de explicitação da subjetividade subjacente à experiência social, neste caso trata-se de uma clínica psicossocial. O termo psicossocial corresponde à composição de um grupo em sua natureza, indissociável, entre o psíquico e o social (MELO; MAIA FILHO; CHAVES, 2014). Neste sentido, a pesquisa psicológica de campo, ou seja, pesquisa-ação implica em clínica do social. Para Lewin (1978, p. 220), "é preciso estabelecer processos de averiguação de fatos, olhos e ouvidos sociais, bem no interior dos corpos de ação social". Esta temática de intervenção e de mudança estaria ligada à aspiração dele de transformar a psicologia social em uma ciência de ação.

Haguette (1997, p. 112) atribui o pioneirismo da intervenção social à Lewin, afirmando que "é, pois, com Kurt Lewin que o conceito de intervenção, na vida social, com o objetivo de transformá-la, toma corpo, e uma metodologia própria começa a se firmar e aperfeiçoar".

Fractal, Rev. Psicol., v. 28 - n. 1, p. 153-159, 2016
Para Lewin (1978), as hipóteses que a ciência formula e as teorias que elabora não tem valor para a psicologia social senão na medida em que são aplicáveis, isto é, na medida em que permitem efetuar, de modo eficaz e permanente, as transformações dos fenômenos sociais que elas querem explicar.

Para Barbier (1985, p. 46), que situa a pesquisa-ação entre a psicologia clínica e a sociologia clínica, o objetivo do método clínico em ciências sociais é

[...] explorar o comportamento e as representações de um sujeito ou de um grupo de sujeitos diante de uma situação concreta, para compreender-lhes o sentido, colocandose alternadamente na perspectiva de observador e na de sujeitos-atores e de sua vivência.

Comparando a atividade do pesquisador com a da clínica médica, Lewin (1978, p. 227) destaca que o pesquisador

[...] terá usualmente de escolher entre diversos métodos de tratamento e precisará de tanta habilidade e engenhosidade quanto o médico, no que se refere ao diagnóstico e ao tratamento.

Para Barbier (1985), o conceito de "clínica" em ciências sociais é um conceito-chave, pois está na confluência da ciência pura com a ciência aplicada no que se refere ao humano. Destaca que o mais importante para o procedimento clínico é a sensibilidade ao que é ambíguo.

A pesquisa-ação visa gerar o empoderamento (empowerment) da comunidade e com isto maior autonomia na resolução de seus problemas. O objetivo de gerar o empoderamento acrescenta à pesquisa-ação um conceito que define melhor o que se espera com a participação neste tipo de investigação. Empoderamento é definido como a relação de poder existente entre as pessoas que convivem juntas diariamente, no sentido do controle de suas próprias vidas (MACHADO et al., 2015).

Stringer (1993) apresenta as premissas fundamentais para gerar o empoderamento. Ele destaca o controle das ações comunitárias e sentimentos de poder sobre tais ações. Salienta as possíveis oportunidades de tomada de decisão que os capacita a definir suas prioridades e determinar sua direção. E também os meios de afetar os eventos e atividades que tem um impacto sobre suas vidas.

Estas são afirmativas de natureza ideal. Elas oferecem a base para o desenvolvimento de critérios através dos quais os pesquisadores podem direcionar as atividades da pesquisa. Programas de cursos e processos de trabalho definidos na sua situação local pelos integrantes da comunidade, de acordo com suas próprias maneiras de interpretar o significado de participação, justiça, liberdade e aperfeiçoamento dos processos de trabalho, geram compromisso e empoderamento. Considerando todos esses aspectos torna-se mais evidente explicitar a proposta da pesquisa-ação.

A ideia Lewin é composta de um ciclo em quatro etapas: coleta de dados, diagnóstico, implementação e avaliação. Na primeira etapa, explora-se o campo, registrando-se os dados relevantes sobre os problemas 
apresentados pela organização-cliente. Estes problemas não são questionados em profundidade, a discussão é mais no sentido de enunciá-los de uma forma clara, constituindo-os no ponto de partida para coletar os dados e realizar o diagnóstico.

Assim, partindo dos problemas apresentados, é realizada uma análise coletiva, para que os problemas venham a revelar-se em sua essência. Alguns problemas são sintomas de outros, embutidos nos processos de trabalho das organizações. A definição do problema inicial orienta os dados a serem investigados e as estratégias e técnicas que serão utilizadas para resolvêlos tais como a observação participante e as oficinas. Neste momento da pesquisa-ação, os problemas são explicitados e hierarquizados. Quivy e Campenhoudt (1992) utilizam o termo "pergunta de partida" para procedimentos semelhantes de escolha do problema, chave principal na pesquisa-ação.

A segunda etapa, o diagnóstico, ocorre através da categorização e análise dos dados. A partir da situaçãoproblema é traçada a situação desejada através da definição de resultados esperados. O diagnóstico é o momento em que, partindo da identificação coletiva dos problemas de uma determinada situação e adotando estratégias de dinâmica dos grupos e conhecimentos das ciências sociais e psicológicas, descortina-se o modo operante, ou seja, os processos de trabalho da organização.

Para realizar o diagnóstico, parte-se do problema apresentado, escolhe-se um método e as técnicas de coleta de dados buscando informações que permitam formar uma compreensão da situação. Buscar dados no objeto-sujeito na pesquisa-ação constitui a estratégia principal para a solução de problemas sociais.

Schein (1982) comenta que entre os valores mais importantes da pesquisa-ação está a realização de um diagnóstico permanente, como alternativa ao "achismo" e generalizações grosseiras através dos quais se tomam decisões nas organizações. Ele parte do pressuposto de que o ritmo de transformação da sociedade é constante e exige um aumento na habilidade da sociedade de diagnosticar-se. Por causa disso, devemos incorporar o diagnóstico contínuo dos processos como um estilo de vida, se quisermos evitar fracassos como profissionais e cientistas. Para ele, a habilidade mais importante que deve ser desenvolvida junto aos integrantes de uma pesquisa “é a habilidade de diagnosticar e trabalhar em seus próprios problemas nas áreas interpessoais, organizacionais e de grupo" (SCHEIN, 1982, p. 134).

Para tanto é necessário apoiar a ação dos integrantes da pesquisa-ação na análise prática do problema de pesquisa e no conhecimento teórico desenvolvido. O coordenador da pesquisa deve estimular e difundir os conhecimentos que permitam aos sujeitos o desenvolvimento da habilidade de diagnosticar. A solução do problema de pesquisa deve ser apoiada pelo estudo teórico dos problemas.
Sobre a escolha do estudo teórico Thiollent (2000, p. 52) afirma que "o tema e as questões práticas a serem tratadas devem ser absolutamente endossadas pelos participantes". Investigador e participantes elucidam a situação-problema para organizar a busca de soluções. Ou seja, a pesquisa-ação é organizada em torno da procura de soluções teóricas e práticas para o problema da investigação. Por conta dos achados do campo e da investigação teórica do tema, o diagnóstico é refeito, quando novas informações são inseridas. Assim, após a análise dos problemas, é definido o tema da pesquisa e o problema central da pesquisa. Como afirma Thiollent (2000, p. 50), "O tema da pesquisa é a designação do problema prático e da área de conhecimento a serem abordados".

Os problemas são organizados em assuntos ou subtemas após uma discussão da qual emerge o tema da investigação; este será dirigido para aquisição de conhecimentos que contribuam para a solução dos problemas. Nesta etapa da pesquisa-ação, o consenso entre os participantes e o pesquisador deve ser buscado.

Com base no diagnóstico e no resultado esperado, são identificadas as lacunas existentes entre "o que é" e “o que deveria ser". É nesta discussão do real com o ideal que se inicia a terceira etapa, o planejamento. Delineiam-se as alternativas de solução que devem ser avaliadas, sendo que o meio para solucionar a situação é decidido coletivamente.

A terceira etapa visa a atenuação da distância entre a situação desejada e a situação-problema, através da implementação do planejamento. A finalidade do planejamento é identificar e operacionalizar uma estratégia para resolvê-la. Assim, a estratégia traçada é executada, podendo atingir os resultados esperados ou não.

O planejamento é um esboço de como resolver os problemas. Corresponde a uma hipótese. Thiollent (2000, p. 56) define hipótese na pesquisa-ação "como suposição formulada pelo pesquisador a respeito de possíveis soluções a um problema colocado na pesquisa". O leitor pode estar estranhando a utilização de hipótese em uma pesquisa qualitativa. De fato, são poucas as modalidades de pesquisa qualitativa que preveem a utilização de hipótese. Mas o autor afirma que na pesquisa-ação

[...] seja como for, podemos considerar que a pesquisa-ação opera a partir de determinadas instruções (ou diretrizes) relativas ao modo de encarar os problemas identificados na situação investigada e relativa aos modos de ação. Essas instruções possuem um caráter bem menos rígido do que as hipóteses, porém desempenham uma função semelhante (THIOLLENT, 2000, p. 33).

No planejamento, encontramos um raciocínio hipotético articulado a uma rede de sub-hipóteses que contribuem para sustentar uma hipótese principal. Como resultado desta articulação é elaborado o planejamento, destinado a eliminar as lacunas diagnosticadas e programam-se as atividades planejadas, as quais produzem os resultados. 
A efetivação da pesquisa-ação caracteriza-se por um processo coletivo de mudança. A modificação é apresentada como passagem de uma situação-problema inicial para uma situação desejada. As mudanças imaginadas são coletivas e progressivamente definidas. Thiollent (2000, p. 51) afirma que "na pesquisa-ação, o caráter normativo das propostas é explicitamente reconhecido".

Portanto, a transformação traçada atravessa o campo social e apenas é possível se um acordo no plano das normas for realizado. Isso exige que as normas sejam evidenciadas na busca de soluções a partir das quais são desencadeadas as transformações no meio social. Para Thiollent (2000, p. 54) "há todo um trabalho sobre a normatividade, muitas vezes negado como tal, que é preciso equacionar no plano metodológico".

Por fim, na quarta etapa, os resultados das realizações são verificados. Visa-se identificar, após as ações executadas e os resultados obtidos, quais as lacunas ainda existentes entre a situação desejada e os resultados alcançados. No decorrer da avaliação, as etapas anteriores são reexaminadas em função dos resultados. Para tanto, é revista a coleta de dados, o diagnóstico, o planejamento e a implementação, constituindo-se assim em um rediagnóstico. Por sua vez, este pode motivar um novo ciclo de pesquisa-ação.

\section{Considerações finais}

A pesquisa-ação desenvolvida por Lewin, sem dúvida, inaugura uma nova estratégia para a intervenção científica no campo social e grupal como destaca Haguette (1997), mas sua importância vai muito além desse fato.

A pesquisa-ação é, na verdade, uma intervenção social que não se limita apenas em descrever e teorizar sobre um problema social do cotidiano real das pessoas, mas em resolvê-lo, efetivamente, enquanto uma prática-teoria que transforma a realidade e contribui para a superação de uma situação-problema que gera sofrimento nas pessoas e suas implicações.

Nesse processo inaugura-se, ou mais que isso, se evidencia a natureza psicossociológica desse fenômeno, pois é o sujeito em ação na interação com o outro que modifica a si e ao outro, ao grupo, e a sociedade onde muitos amparam um, e um representa muitos. Portanto, sociedade, grupo e sujeito já não se encontram mais em oposição, e teoria e prática não se separam, mas se reconstroem em uma unidade que paradoxalmente não era visível.

\section{Referências}

ALVES, A. J. O planejamento de pesquisas qualitativas em educação. Cadernos de Pesquisa, São Paulo, n. 77, p. 53-61, maio, 1991.

BARBIER, R. A pesquisa-ação na instituição educativa. Rio de Janeiro: J. Zahar, 1985.

BARBIER, R. A pesquisa-ação. Brasília: Liber Livro, 2007.

BOGDAN, R.; BIKLEN, S. Investigação qualitativa em educação: uma introdução à teoria e aos métodos. Cidade do Porto: Porto, 1994.
FIGUEIREDO, L. C. M.; SANTI, P. L. R. Psicologia: uma (nova) introdução. São Paulo: EDUC, 2007.

HAGUETTE, T. M. F. Metodologias qualitativas na sociologia. 5 ed. Petrópolis: Vozes, 1997.

LEWIN, K. Teoria de campo em ciência social. São Paulo: Pioneira, 1965.

LEWIN, K. Problemas de dinâmica de grupo. São Paulo: Cultrix, 1978.

LÖWY, M. Ideologia e ciência social: elementos para uma análise marxista. 13. ed. São Paulo: Cortez, 1999.

MACHADO, A. R. M. et al. Potencializando um grupo de terceira idade de uma comunidade rural. Revista da Escola de Enfermagem da USP, São Paulo, v. 49, n. 1, p. 96-103, fev. 2015.

MACIEL, M. I. E. A pesquisa-ação e Habermas: o novo paradigma. Belo Horizonte: UNA, 1999.

MAILHIOT, G. B. Dinâmica e gênese dos grupos. 6. ed. São Paulo: Duas Cidades, 1985.

MELO, A. S. E.; MAIA FILHO, O. N.; CHAVES, H. V. Conceitos básicos em intervenção grupal. Encontro: Revista de Psicologia, [S.1.], v. 17, n. 26, p. 47-63, jul. 2014.

QUIVY, R.; CAMPENHOUDT, L. Manual de investigação em ciências sociais. Lisboa: Gradiva, 1992.

REY, F. L. G. Pesquisa qualitativa em psicologia: caminhos e desafios. São Paulo: Thompson Learning, 2002.

SCHEIN, E. H. Psicologia organizacional. 3. ed. Rio de Janeiro: Prentice Hall do Brasil, 1982.

SCHWANDT, T. A. Três posturas epistemológicas para a investigação qualitativa. In: DENZIM, N. K.; LINCOLN, Y. S. (Col.). O planejamento da pesquisa qualitativa: teorias e abordagens. 2. ed. Porto Alegre: Artmed, 2006. p. 193-217.

SOMMER, R. Action research: from mental hospital reform in Saskatchewan to community building in California. Canadian Psychology/Psychologie canadienne. v. 40, n. 1, p. 47-55, Feb. 1999.

STRINGER, E. T. Socially responsive educational research: linking theory and practice. In: FLINDERS, D.; MILLS, G. E. (Ed.). Theory and concepts in qualitative research: perspectives from the field. New York: Teachers College Press, 1993. p. 141162.

THIOLLENT, M. Pesquisa-ação nas organizações. São Paulo: Atlas, 1998.

THIOLLENT, M. Metodologia da pesquisa-ação. São Paulo: Cortez, 2000.

TRIPP, D. Pesquisa-ação: uma introdução metodológica. Educação e pesquisa, São Paulo. v. 31, n.3, p. 443-466, set./ dez. 2005.

TRIVIÑOS, A. N. S. Introdução à pesquisa em ciências sociais: a pesquisa qualitativa em educação. São Paulo: Atlas, 1992.

WILLIAMSON, G. R.; PROSSER, S. Action research: politics, ethics and participation. Journal of advanced nursing, [S.1.], v. 40, n. 5, p. 587-593, nov. 2002.

Recebido em: 19 de julho de 2013 Aceito em: 16 de julho de 2015 